\title{
Assistência ao surdo na área de saúde como fator de inclusão social
}

\author{
ASSISTANCE TO THE DEAF IN THE HEALTH AREA AS A FACTOR OF SOCIAL INCLUSION
}

ASISTENCIAAL SORDO EN EL ÁREA DE SALUD COMO FACTOR DE INCLUSIÓN SOCIAL

\author{
Neuma Chaveiro', Maria Alves Barbosa ${ }^{2}$
}

\section{RESUMO}

Este estudo objetivou discutir a assistência ao surdo na área de saúde como fator de inclusão social; investigar junto aos surdos como se estabelece o vínculo com os profissionais da saúde; verificar percepções dos surdos quanto à presença de intérpretes de língua de sinais, quando recebem assistência à saúde. Pesquisa descritivo-analítica, com abordagem qualitativa realizada em uma escola especial em Goiânia. A amostra constou de 20 alunos surdos e a entrevista semiestruturada foi utilizada para coletar os dados. Constatou-se que o vínculo é estabelecido quando os profissionais conseguem comunicar-se com os surdos; a inclusão do surdo nos serviços de saúde evidencia dificuldades de comunicação. Concluiu-se que a relação profissional cliente precisa ser melhorada; que o vínculo ocorre quando o cliente se sente compreendido e que a presença do intérprete melhora, mas não contribui totalmente para a inclusão social do surdo.

\section{DESCRITORES}

Pessoas com insuficiência auditiva.

Relações profissional-paciente. Linguagem de sinais.

Prestação de cuidados de saúde.

\begin{abstract}
The purposes of this article are to discuss the assistance to deaf people in the health area as a factor of social inclusion; to investigate with the deaf how the link with health workers is established; and to verify the deaf people's perception of the presence of sign language interpreters when they get health assistance. This is a descriptive and analytical survey with a qualitative approach carried out at a special school in Goiânia. The sample was comprised of 20 deaf students, and semi-structured interviews were used to collect the data. It was verified that the link is established when health workers are able to communicate with the deaf. The inclusion of the deaf in the health services is an evidence of difficulties in communication. It was concluded that the professional-client relationship must be improved, that the link occurs when the client feels himself/ herself understood, and that the presence of an interpreter improves but is not enough to ensure the inclusion of the deaf.
\end{abstract}

\section{KEY WORDS}

Hearing impaired persons.

Professional-patient relations.

Sign language.

Delivery of health care.

\section{RESUMEN}

En este estudio se tuvo como objetivo discutir la asistencia al sordo en el área de salud como factor de inclusión social; investigar junto a los sordos, cómo se establece el vínculo con los profesionales de salud; verificar las percepciones de los sordos en cuanto a la presencia de intérpretes del idioma de señales cuando recibe asistencia a la salud. Investigación descriptivoanalítica, con abordaje cualitativo realizada en una escuela especial en Goiânia. La muestra constó de 20 alumnos sordos y la entrevista semi-estructurada se utilizó para recolectar los datos. Se constató que el vínculo se establece cuando los profesionales consiguen comunicarse con los sordos; la inclusión del sordo en los servicios de salud evidencia dificultades de comunicación. Se concluyó que la relación profesionalcliente requiere ser mejorada; que el vínculo ocurre cuando el cliente se siente comprendido y que la presencia del intérprete mejora, mas no contribuye totalmente a la inclusión del sordo.

\section{DESCRIPTORES}

Personas con deficiencia auditiva.

Relaciones profesional-paciente. Lenguaje de signos.

Prestación de atención de salud.
1 Fonoaudióloga especialista em linguagem pelo Conselho Federal de Fonoaudiologia. Fonoaudióloga do Centro Estadual de Apoio ao Deficiente do Estado de Goiás (CEAD). Intérprete da Língua Brasileira de Sinais (LIBRAS).

neumachaveiro@ig.com.br

2 Professora Doutora da Faculdade de Enfermagem da Universidade Federal de Goiás (UFG).Doutora em Enfermagem pela Universidade de São Paulo - USP. Diretora e administradora da Faculdade de Enfermagem da UFG. 


\section{INTRODUÇÃO}

A inclusão social referente ao atendimento aos portadores de necessidades especiais, nos serviços da área de saúde, estabelece-se como fator essencial de qualidade dos serviços prestados, enquanto que a falta de comunicação inviabiliza um atendimento humanizado. A comunicação com os surdos surge como um desafio aos profissionais que lhes prestam assistência à saúde.

Compreender o processo de inclusão social que é proposto hoje à sociedade exige conhecimento da história sobre como foram tratadas as pessoas com deficiências, explicitada em quatro momentos distintos, a saber: exclusão, segregação, integração e inclusão.

No período compreendido entre o final do século XIX até a década de 1940, a sociedade vivenciou a política da exclusão e segregação. Na exclusão os deficientes eram considerados inválidos, inúteis, chegando, em algumas culturas, ao extermínio. Já no século XX a fase da segregação se instaura, criaram-se grandes instituições para abrigá-los, em regime de internato, um progresso da humanidade, visando apenas ao bem-estar da pessoa com deficiência, período eminentemente assistencial ${ }^{(1)}$.

O movimento da integração ocorreu nas décadas de 1950 a 1980 contra a política de segregação, induzindo as pessoas com deficiência ao máximo esforço para reverter o quadro e conseguir sua adaptação ao meio social. Em caso de êxito seriam integradas, ao contrário, continuariam à margem da sociedade ${ }^{(1)}$.

A fase de inclusão surgiu na década de 1980 e está em plena discussão nos dias atuais. Surge a concepção de que a família e a sociedade devem adaptar-se às necessidades de todas as pessoas, sejam elas deficientes ou não. A imagem da pessoa com deficiência é de alguém que possa desenvolver e exercer sua cidadania, com autonomia e liberdade, numa sociedade na qual ela tem direitos e sobre a qual ele tem deveres ${ }^{(2)}$.

Conviver no universo das pessoas com deficiência envolve uma mudança de paradigmas. Para os surdos, as mudanças acontecem quando são aceitos e respeitados em suas diferenças e contar com a presença de intérpretes da Língua Brasileira de Sinais (LIBRAS), no atendimento aos surdos é exemplo de valorização das diversidades.

O valor fundamental da linguagem está na relação em que as pessoas se fazem entender umas às outras. Quando compartilha-se experiências de for- ma eficaz é possível reconhecer as percepções de dor ou prazer expressas pelo outro, por meio de aspectos verbais e não-verbais da comunicação ${ }^{(3-4)}$.

A comunicação não-verbal é de extrema importância no atendimento aos pacientes e permite a excelência do cuidar em saúde, o profissional que a reconhece adequadamente remete significado aos sinais não verbais potencializando suas interações ${ }^{(3)}$.

Como são compartilhadas as experiências de atendimento dos surdos? A sua linguagem não-verbal é compreendida pelos profissionais da saúde? $\mathrm{O}$ vínculo estabelecido é suficiente para garantir uma assistência humanizada? Necessário faz-se ouvir a comunidade surda sobre essas questões.

Os surdos apresentam uma perda auditiva, problema de ordem sensorial, o que dificulta sua comunicação pelas línguas orais, determinando a necessidade de recorrer a um outro canal para se expressar, a língua de sinais ${ }^{(5)}$.

As línguas de sinais são de modalidade vísuoespacial ou espaço-visual, pois o sistema de signos compartilhados é recebido pelos olhos e sua produção realizada pelas mãos. As línguas de sinais são reconhecidas enquanto línguas pela lingüística, que lhes atribui o conceito de línguas naturais ou como um sistema lingüístico legítimo e não as considera como problema do surdo ou como patologia da linguagem ${ }^{(6)}$.

As línguas de sinais estão presentes nos cinco continentes, mas não são universais, cada uma tem sua própria estrutura gramatical, sendo que com as línguas de sinais é possível expressar qualquer conceito complexo, sutil ou abstrato. Elas possuem estruturas próprias que independem das línguas oraisauditivas ${ }^{(7)}$. As línguas de sinais são um sistema lingüístico altamente estruturado e tão complexo como as línguas faladas, estruturando-se neurologicamente nas mesmas áreas cerebrais das línguas orais $^{(8)}$

De acordo com o Ministério da Educação do Brasil:

As garantias individuais do surdo e o pleno exercício da cidadania alcançaram respaldo institucional decisivo com a Lei Federal no 10.436, de 24 de abril de 2002, em que é reconhecido o estatuto da Língua Brasileira de Sinais como língua oficial da comunidade surda, com implicações para sua divulgação e ensino, para o acesso bilíngüe à informação em ambientes institucionais e para a capacitação dos profissionais que trabalham com os surdos(9). 
Cabe agora às instituições públicas e à sociedade de modo geral proporcionar meios para que a inclusão social possa verdadeiramente acontecer. Ressalta-se, aqui, a importância do Art. $3^{\circ}$ da Lei Federal $\mathrm{n}^{\circ} 10.436 / 02$, descrito a seguir:

As instituições públicas e empresas concessionárias de serviços públicos de assistência à saúde devem garantir atendimento e tratamento adequado aos portadores de deficiência auditiva, de acordo com as normas legais em vigor ${ }^{(9)}$.

A linguagem é um instrumento de poder e aos surdos não pode ser negado o direito de usufruir os benefícios de uma língua, portanto, aceitar a diferença do surdo e conviver com a diversidade humana é um desafio proposto à sociedade, incluindo o adequado atendimento na área da saúde para os surdos, diante de suas necessidades.

A barreira de comunicação é verificada na interação entre surdos - profissionais de saúde, portanto, torna-se indispensável que ambos encontrem formas de interagirem-se para garantir uma assistência de melhor qualidade ${ }^{(4)}$.

A jornalista Claúdia Werneck ressalta que a violação dos direitos de pessoas com deficiência é maior do que podemos imaginar. Ao receber um grupo de alunos de medicina para entrevista sobre inclusão, um dos universitários relatou o seguinte fato:

Havia, na ala de queimados do hospital público em que ele atuava, um homem bastante machucado, que praticamente não se queixava de dor, o que chamava a atenção de médicos, enfermeiros e atendentes. Ele não recebia visitas de familiares, amigos, era muito solitário. As anotações em seu prontuário no que se referia a analgésicos eram raríssimas, fato não compatível com seu estado. Até que um médico resolveu esclarecer este mistério e descobriu que este paciente era surdo, não-oralizado, e sentia muita dor, sim, só não conseguia expressar isso, por que, imobilizado por causa das queimaduras, não mexia as mãos nem outras partes de seu corpo $^{(10)}$.

Ser cidadão brasileiro, vivenciar a mesma cultura das pessoas ouvintes não garante aos surdos atendimento igualitário na área da saúde, uma barreira é imposta aos surdos e profissionais por não compartilharem uma mesma linguagem.

Uma proposta de atendimento inclusivo na área da saúde envolve, portanto, um sistema que identifique-se com princípios humanistas e cujos profissionais tenham um perfil que seja compatível com esses princípios.

\section{OBJETIVOS}

- Discutir a assistência ao surdo na área de saúde como fator de inclusão social;

- Investigar, junto aos surdos, como se estabelece o vínculo com os profissionais quando necessitam de atendimento na área de saúde;

- Verificar percepções dos surdos quanto à presença de intérpretes de Língua de Sinais, quando recebe assistência à saúde.

\section{MÉTODO}

Este estudo de natureza descritivo-analítica, com abordagem qualitativa, foi desenvolvido na Escola Especial Elysio Campos, que mantêm convênio com a Associação de Surdos de Goiânia.

A pesquisa foi desenvolvida no início de 2004 A amostra estudada constou de 20 alunos surdos, com idade acima de 18 anos. O instrumento utilizado para a coleta de dados foi uma entrevista, contendo questões que abordavam aspectos do atendimento ao surdo na área de saúde, como: o vínculo estabelecido com profissionais; as dificuldades de comunicação; fatos positivos e negativos relativos à assistência à saúde; a presença do intérprete de LIBRAS no atendimento, explicitando suas dúvidas e percepções.

As questões foram explicadas e traduzidas em LIBRAS - Língua Brasileira de Sinais - a cada indivíduo, e no decorrer da coleta surgiram outros dados. Vale ressaltar que estes dados surgiram do próprio interesse dos surdos entrevistados, sem interferência das autoras.

A técnica utilizada para análise de dados foi análise de conteúdos, tipo análise temática, que

consiste em descobrir os 'núcleos de sentido' que compõem a comunicação e cuja presença ou freqüência de aparição podem significar alguma coisa para o objetivo analítico escolhido(11).

O trabalho foi desenvolvido posteriormente à aprovação de seu projeto no Comitê de Ética em Pesquisa Médica Humana e Animal do Hospital das Clínicas da Universidade Federal de Goiás, atendendo à resolução 196/96 da Comissão Nacional de Ética em Pesquisa-CONEP.
Assistência ao surdo na área de saúde como fator de inclusão social 
Neuma Chaveiro

Maria Alves Barbosa

\section{RESULTADOS E DISCUSSÃO}

Os resultados obtidos pela pesquisa promoveram uma série de conhecimentos sobre a assistência ao surdo na área da saúde, na visão dos próprios surdos.

No intuito de não alterar e desfigurar o discurso dos surdos optou-se por reproduzi-los na íntegra, traçando paralelamente análise e discussão dos resultados, estabelecendo comentários e considerações.

Fala-se, cada vez mais, em inclusão das pessoas com deficiência na sociedade. Percebeu-se que elas não precisam "preparar-se" para a escola, o trabalho ou o lazer, mas a sociedade deve adaptar-se para atender às suas necessidades, trazer para dentro do sistema os grupos de "excluídos" e, paralelamente, melhorar a qualidade de vida de todos.

No presente estudo, em relação à assistência ao surdo na área de saúde como fator de inclusão social os resultados foram:

Agora está tudo melhor, uma surda minha amiga deu-me um cartão de uma médica ginecologista que sabe LIBRAS, tudo ficou mais fácil e muito melhor, a comunicação foi estabelecida, não tenho mais dúvidas. (S2)

Temos hoje um grande desafio: como cada indivíduo e profissional pode contribuir para a implementação de uma sociedade inclusiva que saiba conviver com as diversidades? Não importa que atividade profissional uma pessoa irá exercer, em diferentes situações ela deverá lidar com pessoas que têm deficiência: pacientes, alunos, leitores, funcionários, amigos, professores ${ }^{(12)}$.

A necessidade dos surdos serem compreendidos pelos profissionais de saúde, torna-se visível nos seus relatos:

Tive dengue e o médico não explicou. Sei que tive porquê aqui na escola a professora falou que dengue dá febre, dor, mas eu não sabia que doença era. (S17)

Tenho dificuldades. É muito difícil a comunicação com os profissionais da saúde. (S10)

As pesquisas que abordam o uso da LIBRAS pelos profissionais da saúde são poucas. Observase que o comportamento não verbal impede um vínculo efetivo entre cliente e profissional, portanto, em sua formação é essencial o aprendizado da LIBRAS $^{(4)}$ como sugerem também os surdos neste estudo.
Os profissionais da saúde precisam aprender LIBRAS nos seus cursos de graduação. S18

Se souberem LIBRAS como a ginecologista e os enfermeiros tudo será mais fácil. S2

Por que, então, não se preparar? Para aceitarmos o surdo precisamos aceitar sua língua, sua forma de comunicar e entrosar-se com o mundo. Cabe aos profissionais da saúde, às faculdades o importantíssimo papel de prepararem-se para essa realidade.

Não foram encontradas referências mostrando a existência, na grade curricular dos cursos superior de enfermagem, de disciplina que contemple as condições de saúde dos deficientes, seus direitos e necessidades, o que possibilitaria um atendimento humanizado aos $\operatorname{surdos}^{(13)}$.

Pelo fato dos surdos muitas vezes não terem problema visual, a escrita poderia ser uma alternativa, mas a realidade não é assim, para eles o português é a segunda língua, e como qualquer língua estrangeira, é difícil seu aprendizado. Deste modo, um dos grandes desafios na área de educação é a sua alfabetização. Portanto, a escrita como apontada por alguns surdos na pesquisa não é o caminho ideal para eficácia do atendimento.

Escrever apenas não resolve os problemas, é necessário que eles expliquem. (S4)

Pensam que sabemos bem o português, e que só pela escrita revolveria tudo, mas não é assim. (S3)

O direito à saúde é um bem fundamental, no entanto, para os surdos, esse direito parece não estar sendo resguardado. Os depoimentos evidenciam dificuldades de comunicação com os profissionais da saúde, relatadas em $100 \%$ dos entrevistados (20 sujeitos).

Em relação ao vínculo estabelecido com os profissionais da saúde os resultados foram:

Eu já estive doente e não fui ao médico, porque tive medo de não ser compreendida, tive que esperar mais ou menos cinco dias para minha mãe chegar e ir comigo. (S4)

Quando precisava ir ao médico pedia para minha irmã escrever o que eu estava sentindo, mostrava para o médico e ele me dava a receita. $O$ médico não explicava nada, eu ficava com muitas duvidas, eles não entendem nossa vida. (S10)

O bloqueio de comunicação entre surdos e profissionais da saúde instaura-se como um dos grandes obstáculos da comunidade surda, quando procura serviços de saúde. O indivíduo surdo precisa 
ser assistido de forma global, respeitadas suas crenças, seus valores e diferenças ${ }^{(13)}$.

O profissional que norteia seu trabalho com uma práxis na assistência que valoriza a qualidade do cuidado em saúde, foi explicitado também nos depoimentos dos surdos.

Encontrei uma médica ginecologista que não sabe LIBRAS, mas tem paciência, explica, escreve, mostra figuras, ela é muito boa. (S14)

Quando era criança, o médico não deixava fazer sinais, mandava ficar com a mão parada, tinha que falar. Mas, agora melhorou muito, no consultório posso usar LIBRAS. (S16)

As dificuldades de comunicação podem se tornar uma barreira ao sucesso do atendimento. Muitas vezes com grandes dificuldades, os surdos conseguem apenas descrever seus sintomas, caracterizados então como objeto da prática de saúde ${ }^{(4)}$.

Refletir sobre os entraves causados por um diálogo ineficiente poderá evitar desordens mais complexas como o fato ocorrido com um dos sujeitos.

Tive apendicite (...). Meu esposo também é surdo, (...). No primeiro hospital que fui deram-me remédio e falaram que podia voltar para casa que não era nada sério. A dor só aumentava, procuramos outro hospital, não conseguiram nos entender, aplicaram uma injeção (...). Já não suportava de tanta dor, foi quando chegou em casa nossos amigos, um casal de surdos, eles tinham carro, fomos buscar uma sobrinha minha, ouvinte, para ir junto ao hospital, só assim recebi atendimento. Fui operada, o apêndice supurou. Fiquei internada 9 dias, ninguém pôde ficar comigo, estava sozinha, os profissionais do hospital não sabiam conversar comigo, passei mal, chorei, tudo sozinha. (S3)

Este relato mostra que ainda vivenciamos a exclusão na assistência à saúde oferecida aos surdos, uma "sociedade para todos" que valorize a diversidade, está a desejar.

A força da legislação não tem sido suficiente para atingir a sociedade brasileira no que se refere à inclusão. Avançamos, mas ainda continuamos pensando e agindo no âmbito do conceito da integração, as pessoas precisam estar prontas para conviver nos sistemas sociais $^{(1)}$.

A boa ou má interação é claramente percebida quando os surdos procuram atendimento à saúde, as imposições para adaptarem-se ao sistema são grandes, e, não conseguindo, estão absolutamente exclusos. As dificuldades têm início na sala de espera.
Na hora de fazer a ficha é difícil, quando a secretária chama pelo nome é difícil. Bom é quando chama pelo "placar" com números. (S1)

As dificuldades começam com a secretária, não consigo explicar porque estou ali. (S9)

A falta de intérpretes de LIBRAS constitui-se uma barreira nas instituições de saúde do Brasil, o que torna ainda mais complicada a vida das pessoas com surdez que procuram atendimento ou que solicitam ajuda nestas instituições ${ }^{(12)}$.

Não se concebe instituições que não ofereçam ao surdo, intérpretes e profissionais capazes de comunicarem-se com eles, da mesma forma que não se concebe instituições que não tenham rampas ou elevadores. Não adaptar às necessidades dos grupos minoritários é um fator de exclusão social.

Em relação a percepção dos surdos quanto a presença dos intérpretes de LIBRAS os resultados foram:

Com ele fica mais fácil, mas é preciso ter confiança no intérprete. (S10)

Precisa de mais intérpretes, que possam acompanhar os surdos, mas não por piedade. (S14)

Na coleta de dados observou-se que os surdos valorizam a presença do intérprete, mas com algumas ressalvas: a confiança, o tempo disponível, o constrangimento de se expor frente ao intérprete, sentimentos de piedade, enfim...

\section{É difícil depender da boa vontade e do tempo dos intérpretes, por isso vou sozinho. (S13)}

Tinha vergonha de expor algumas coisas na frente do intérprete. (S5)

Observamos a dificuldade de encontrar intérprete para uma assistência em saúde, ficando a responsabilidade sobre a família do surdo.

Preciso ir sempre com um parente, irmão ou mãe, mas eles não sabem LIBRAS. É difícil. (S1)

Eu tenho uma filha que hoje é intérprete, mas antes tudo foi muito difícil. Para os outros surdos que não têm a mesma sorte que eu é difícil. (S19)

A presença do intérprete de LIBRAS para surdos é essencial, mas não prepara o profissional para uma inclusão efetiva. No dia em que o tradutor falta, não está disponível para acompanhar os surdos, ou mesmo até quando se faz presente, pode dificultar a interação: paciente-profissional da saúde, embora a contratação do profissional intérprete seja correta, ressente-se a ausência de uma reflexão mais aprofundada sobre a diversidade, porque reduz o seu
Assistência ao surdo na área de saúde como fator de inclusão social 
Neuma Chaveiro

Maria Alves Barbosa alcance ao limite de providência pontual, descontextualizada de uma verdadeira perspectiva da inclusão ${ }^{(12)}$

A comunicação é indicativo de qualidade de vida, portanto, quando os profissionais sabem comunicarem-se com os surdos, promovem uma assistência na área de saúde humanizada e focalizada no contexto de uma sociedade inclusiva.

\section{CONCLUSÃO}

Na sociedade atual preconiza-se a convivência com as diferenças. Várias medidas são adotadas nas instâncias Federal, Estaduais e Municipais, asseguradas pela Constituição Brasileira, tentando garantir a inclusão das pessoas com surdez no cotidiano familiar, coletivo e institucional. Aos profissionais da saúde torna-se indispensável buscar novos paradigmas que facilitem promover uma assistência à saúde de qualidade e humanizada.

A relação profissional da saúde e cliente surdo precisa ser melhorada, porque para os surdos o atendimento digno é atingido quando são compreendidos em suas necessidades, efetivando assim a inclusão na saúde.

A comunicação estabelecida com os surdos, instaura-se como um dos grandes obstáculos do cui- dar em saúde. O bloqueio de comunicação prejudica o vinculo entre profissionais da saúde e surdos, comprometendo o atendimento.

Imagina-se que a presença do intérprete solucionaria todos os problemas de comunicação, entretanto, verifica-se que nem sempre é assim que ocorre. A atuação do intérprete melhora, mas não contribui totalmente para a inclusão do surdo.

Diante desse panorama a realização deste estudo foi importante e oportuna. As percepções dos surdos em relação aos atendimentos no sistema de saúde, constituem-se de dados imprescindíveis para sua inclusão social, respeitando e valorizando as diferenças, melhorando conseqüentemente a qualidade da assistência em saúde.

A discussão da assistência à saúde, como fator de inclusão social, não se encerra neste estudo, mas sinaliza para a necessidade de novas pesquisas que sensibilizem e esclareçam os profissionais da saúde para bem atender à comunidade surda.

Responder às dificuldades dos surdos quando procuram atendimento à saúde é dever de todos profissionais comprometidos em colaborar na construção de uma sociedade inclusiva.

\section{REFERÊNCIAS}

(1) Sassaki RK. Inclusão: construindo uma sociedade para todos. Rio de Janeiro: WVA; 1997.

(2) Santos MP. A formação de professores no contexto da inclusão. In: Anais do $2^{\circ}$ Congresso Internacional do INES; 2003 set. 17-19; Rio de Janeiro. Rio de Janeiro: INES; 2003. p. 65.

(3) Silva MF, Silva MJP. A auto-estima e o não-verbal dos pacientes com queimaduras. Rev Esc Enferm USP 2004; 38(2):206-16.

(4) Barbosa MA, Oliveira MA, Siqueira KM, Damas KCA, Prado MA. Linguagem Brasileira de Sinais Um desafio para a assistência de enfermagem. Rev Enferm UERJ 2003; 11(3):247-51.

Av. K, esq. com 6-A n. 138 - Ap. 101 Edif. Sândalo - Goiânia CEP - 74075-200 - GO

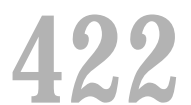

Rev Esc Enferm USP 2005; 39(4):417-22. ra. Estudos lingüísticos. Porto Alegre: Artmed; 2004.
(6) Quadros RM, Kanopp LB. Língua de Sinais Brasilei- dos (FENEIS). O que é o intérprete de língua de sinais? [online] Rio de Janeiro; [s.d.] Disponível em < http://www.feneis.br> (31 jan. 2004)
(7) Brito LF. Integração social \& educação de surdos. Rio de Janeiro: Babel; 1993.

(8) Hickok G, Berllugi U, Klima ES. A língua de sinais no cérebro. Rev Scientific Am Bras [s.d.]; Ed. esp. (4):50-7.

(9) Ministério da Educação e Cultura. Ensino de língua portuguesa para surdos. Brasília; 2002. v. 1.

(10) Werneck C. Sou humano. Educ Fam - Deficiências A diversidade faz parte da vida 2004; 1(5):58-61.

(11) Bardin L. Análise de conteúdo. Lisboa: Edições 70; 1979.

(12) Veet V,coordenador. Mídia e deficiência. Brasília: Fundação Banco do Brasil; 2003. (Série diversidade)

(13) Santos EM, Shiratori K. As necessidades de saúde no mundo do silêncio: um diálogo com os surdos. Rev Eletrôn Enferm [periódico online] 2004; 6(1). Disponível em:<http://www.fen.ufg.br.> (30 ago. 2004) 